\title{
Iron regulation by hepcidin
}

\author{
Ningning Zhao, An-Sheng Zhang, and Caroline A. Enns \\ Department of Cell and Developmental Biology, Oregon Health and Science University, Portland, Oregon, USA.
}

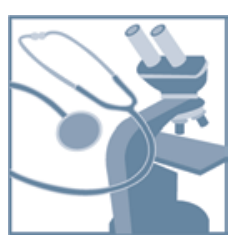

Hepcidin is a key hormone that is involved in the control of iron homeostasis in the body. Physiologically, hepcidin is controlled by iron stores, inflammation, hypoxia, and erythropoiesis. The regulation of hepcidin expression by iron is a complex process that requires the coordination of multiple proteins, including hemojuvelin, bone morphogenetic protein 6 (BMP6), hereditary hemochromatosis protein, transferrin receptor 2, matriptase-2, neogenin, BMP receptors, and transferrin. Misregulation of hepcidin is found in many disease states, such as the anemia of chronic disease, iron refractory iron deficiency anemia, cancer, hereditary hemochromatosis, and ineffective erythropoiesis, such as $\beta$-thalassemia. Thus, the regulation of hepcidin is the subject of interest for the amelioration of the detrimental effects of either iron deficiency or overload.

\section{Discovery and function of hepcidin in iron homeostasis}

Hepcidin is a key peptide hormone that regulates iron homeostasis in chordates. Hepcidin was initially characterized as an antimicrobial peptide in a mass spectrometry-based search for cysteine-rich defensin-like peptides in blood (1) and in urine (2). However, both groups showed that hepcidin displays only a weak antimicrobial activity. Further, unlike defensins, which vary in sequence among species, hepcidin is highly conserved from zebrafish to humans. Shortly after hepcidin was described, subtractive hybridization studies comparing the livers of normal and iron overloaded mice established a connection between iron loading and increased hepcidin mRNA $(3,4)$. The fundamental insight into hepcidin's role in iron homeostasis came in 2004 with the discovery that hepcidin acts to lower iron in the blood by binding to and downregulating the iron transporter, ferroportin (FPN1) (5). FPN1 is the only known transporter that is responsible for the efflux of iron from cells. Downregulation of FPN1 by hepcidin in splenic and hepatic macrophages decreases the ability of macrophages to export recycled iron from senescent rbcs, which constitute the primary source of iron in the plasma. In addition, a high concentration of hepcidin in the blood decreases the transport of iron out of intestinal epithelial cells, further limiting iron in the blood.

\section{Control of hepcidin expression}

Hepcidin is synthesized, processed to an active form, and secreted predominantly by hepatocytes $(6,7)$. The expression of hepcidin is mediated through the bone morphogenetic protein (BMP) and JAK2/STAT3 signaling pathways (Figure 1). Under nonpathological conditions, iron levels in the body upregulate hepcidin expression. Although the underlying mechanisms are poorly understood, recent studies have documented the essential roles of hemojuvelin (HJV), hereditary hemochromatosis protein (HFE), transferrin receptor 2 (TfR2), and matriptase-2 (MT2, encoded by the gene TMPRSS6) in the process of hepcidin regulation in humans and animal models as well as of BMP6, neogenin, and BMP receptors (ActRIIA/ALK2/ALK3) in animal models (8-17).

Intact BMP signaling is essential for hepcidin expression. The canonical BMP-signaling pathway is initiated upon BMP binding to a BMP receptor complex on the cell surface, which activates the receptor kinase to phosphorylate the cytoplasmic proteins SMAD1,

Conflict of interest: The authors have declared that no conflict of interest exists. Citation for this article: J Clin Invest. 2013;123(6):2337-2343. doi:10.1172/JCI67225.
SMAD5, and SMAD8. These phosphorylated, receptor-regulated SMADs then form transcription factor complexes with SMAD4, consisting of receptor-regulated SMADs and SMAD4, that translocate into the nucleus to induce the transcription of target genes such as hepcidin (18). In mice, liver-specific disruption of SMAD4 or the BMP receptors ALK2 or ALK3 markedly decreased hepcidin expression, resulting in iron overload $(15,19)$.

BMP6. At least $20 \mathrm{BMPs}$ are expressed in mammals. In vitro studies reveal that BMP2, $-4,-5,-6,-7$, and -9 can robustly induce BMP signaling and markedly increase hepcidin expression in isolated hepatocytes $(11,20,21)$. However, global disruption of Bmp6 in mice reduced hepcidin expression and caused severe iron overload $(10,11)$, indicating that BMP6 plays a pivotal role in the maintenance of iron homeostasis that cannot be compensated by other BMPs. The importance of BMP6 in regulating hepcidin expression is most likely due to its upregulation by iron in the liver (22-25). BMP6 expression is detected mainly in the nonparenchymal cells of the liver, especially in sinusoidal endothelial cells that are in close contact with the circulation (26). Thus the nonparenchymal cells in the liver likely play an important role in iron homeostasis by acting as a source of BMP6 to modulate hepatic hepcidin expression (Figure 1A). However, the mechanism by which hepatic iron levels regulate BMP6 remains to be determined.

Hepatic HJV is an indispensable BMP coreceptor. HJV (also known as hemochromatosis type 2a [HFE2A]) is a glycosylphosphatidylinisotol-linked (GPI-linked) membrane protein. In the liver, HJV is exclusively expressed in hepatocytes $(16,26)$ and acts as a coreceptor for BMP6 to induce hepcidin expression via the BMP signaling pathway $(11,20,27)$, presumably by using ActRIIA in combination with either ALK2 or ALK3 (28). Homozygous or compound heterozygous mutations of HJV in humans markedly reduce hepcidin expression and cause juvenile hemochromatosis $(29,30)$, one of the most severe forms of the iron overload disorders. In $\mathrm{Hjv}^{/-}$mice, hepcidin expression was low despite increased BMP6 expression in the liver (25) indicating an essential role for HJV in BMP6 regulation of hepcidin. The increase in hepatic BMP6 expression in these mice results from the severe iron overload. HJV also interacts with neogenin (31). Neogenin is a ubiquitously expressed membrane protein (32). Neogenin deficiency in neogenin mutant mice abolished hepcidin expression and resulted in severe iron overload that is indistinguishable from that in $\mathrm{Hjv}^{-/-}$mice (16). Although these mutant mice died a few weeks after birth, these observations suggest a potential role of neogenin for the proper function of HJV. 
A

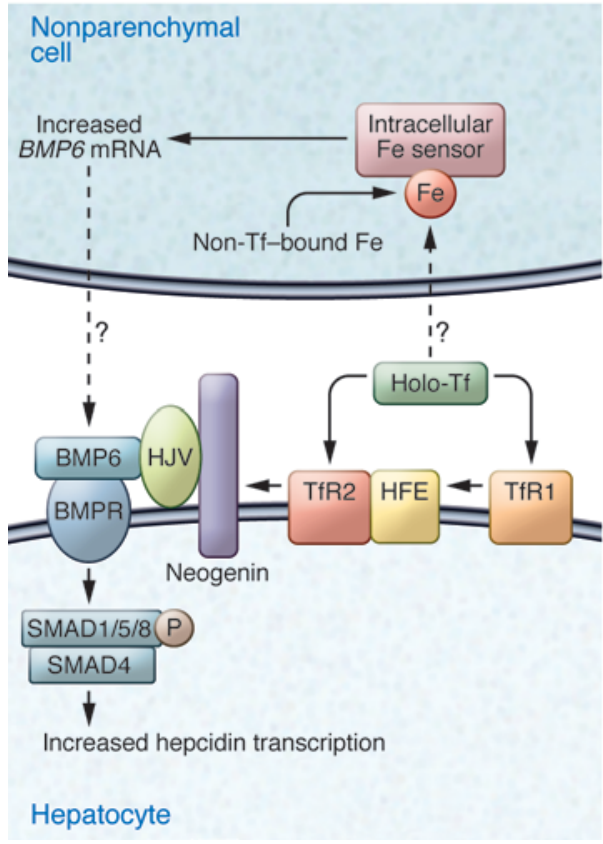

B
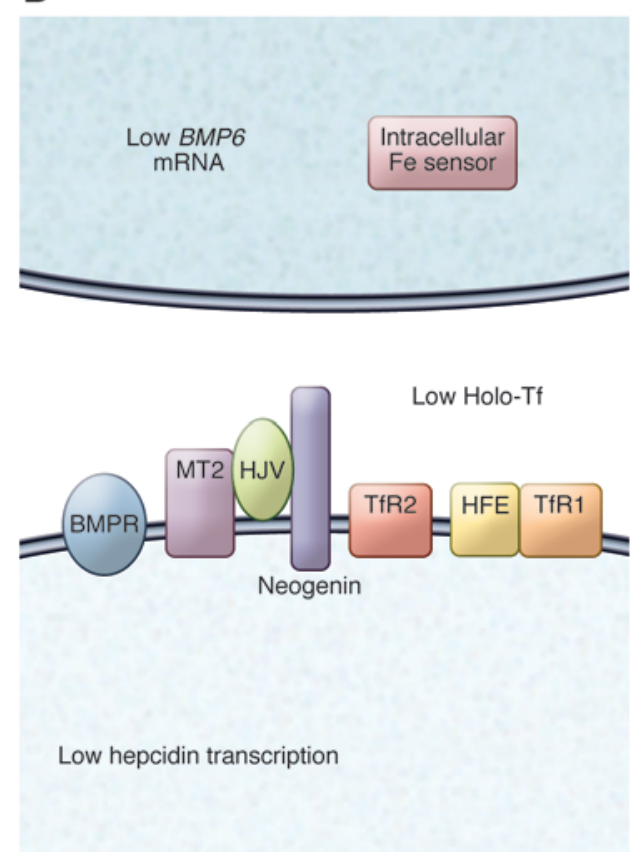

C

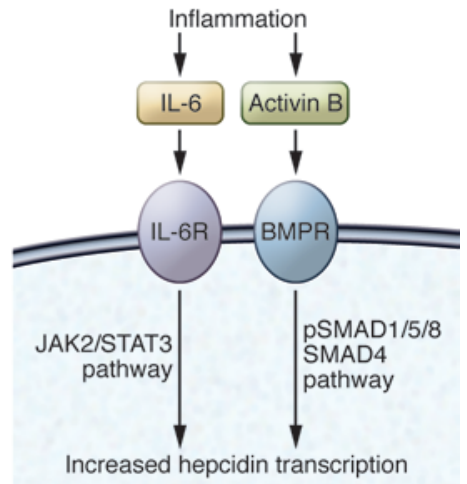

Figure 1

Models for control of hepcidin expression by iron. Efficient hepcidin expression in hepatocytes requires an intact BMP signaling pathway, HJV, neogenin, TfR2, HFE, and BMP6. (A) Under high iron conditions, increased loading of Tf with iron stabilizes TfR2, disrupts the HFE-TfR1 interaction, and induces BMP6 secretion from the nonparenchymal cells of the liver, which facilitates the formation of a complex consisting of the BMP receptor/BMP6/HJV/neogenin/TfR2/HFE to induce hepcidin expression. (B) Low iron conditions increase MT2, which induces the cleavage of hepatic HJV. Decreased Tf saturation in the circulation destabilizes TfR2 protein and facilitates the HFE-TfR1 interaction. Low iron levels in the liver reduce BMP6 secretion from the nonparenchymal cells, consequently blunting BMP signaling and lowering hepcidin expression. (C) Inflammation induces the expression of IL-6 and activin B in the liver, which activates the transcription of hepcidin via the STAT3/JAK2 pathway and the BMP signaling pathway, respectively.

$\mathrm{HJV}$ is also expressed in skeletal and heart muscle. In the $\mathrm{C} 2 \mathrm{C} 12$ murine myoblast cell line, membrane-bound HJV can be released from cells upon cleavage by the ubiquitously expressed furin, a proprotein convertase $(33,34)$. Cleaved soluble HJV is detectable in the serum, and its level in the circulation is elevated upon acute iron deficiency $(35,36)$. Soluble $\mathrm{HJV}$, which was originally suggested to derive from muscle, binds BMP6 and a variety of other BMPs (11, $20,37)$. Soluble HJV has been implicated in suppressing hepcidin expression by acting as a decoy to compete with hepatic HJV for BMP6 $(11,27)$. More recent studies in conditional knockout mice indicated that only the hepatic HJV is necessary for iron homeostasis $(38,39)$. However, these results do not rule out the possibility that soluble HJV acts as a suppressor of hepcidin expression.

Hepcidin regulation by HFE and TfR2. HFE interacts with TfR2 (40, 41 ) and both are predominantly expressed in hepatocytes (42). Hereditary hemochromatosis $(\mathrm{HH})$, the most common form of iron overload disease, is most frequently due to a C282Y mutation in HFE, but can also derive from mutations in TfR2 (17). In spite of elevated liver BMP6 expression in $\mathrm{Hfe}^{-/-}$or $\mathrm{Tfr} 2^{-/}$mice, iron overload is associated with attenuated BMP signaling and decreased hepcidin expression $(43,44)$. These results imply that HFE and TfR2 do not upregulate BMP6 expression directly. Given that $\mathrm{Hfe}^{-/-}$and $\mathrm{Tfr}^{-/-}$mice have lower hepcidin levels for the degree of iron loading, these results also indicate that high BMP6 expression cannot completely compensate for lack of HFE or TfR2.
The mechanism by which HFE and TfR2 regulate hepcidin expression is still controversial. One study indicated that HFE and TfR2 act as a complex to facilitate hepcidin expression through the same pathway, in which HFE is a limiting factor (40). Disruption of either Hfe or Tfr2 in mice attenuated the BMP signaling $(43,44)$. Other studies showed that disruption of both Hfe and Tfr2 in mice causes even lower hepcidin expression and more severe hepatic iron overload than inactivation of a single gene, which implies that $H f e$ and $T f r 2$ regulate hepcidin expression through distinct pathways $(45,46)$. A recent in vitro study suggested that both HFE and TfR2 bind HJV (47). In conjunction with the findings that iron loaded transferrin (Tf) stabilizes TfR 2 by redirecting it to a recycling pathway (48), we hypothesize that HFE and TfR2 regulate hepcidin expression by their interaction with HJV. Under conditions of high Tf saturation, the combination of decreased HFE-TfR1 interaction and the increased stability of TfR 2 would stabilize the association of HFE and TfR2 with HJV. Consequently, the complex would facilitate HJV-induced hepcidin expression (Figure 1A). Conversely, during iron deficiency, $\mathrm{Tf}$ saturation would decrease. The interaction between HFE and TfR1 would increase, TfR2 levels would decline due to more rapid turnover, and the association of HFE and TfR2 with HJV would decrease, leading to a downregulation of hepcidin expression (Figure 1B). This hypothesis remains to be tested in vivo. 
MT2 is a key suppressor of hepcidin expression. MT2 is a membrane serine protease that is expressed mainly in the liver (49). MT2 mutations in humans or lack of MT2 in mice results in increased hepcidin expression and iron refractory iron deficiency anemia (IRIDA) (12-14). Thus, MT2 is a key negative regulator of hepcidin expression. MT2 interacts with HJV, which is the only known substrate of MT2, and both are expressed in hepatocytes. MT2 likely suppresses hepcidin expression by releasing HJV from hepatocytes, thus abolishing HJV's ability to act as a BMP coreceptor (50). Iron deficiency anemia (IDA) resulting from mutations in MT2 is dependent on the presence of functional BMP6, implying that MT2 affects the BMP-signaling pathway (51). MT2 also interacts with neogenin and forms a tertiary complex with both neogenin and HJV. Studies in transfected cells indicated that the MT2-neogenin complex facilitates HJV cleavage by MT2 (52). Additionally, recent studies implicate MT2 as a genetic modifier of the HFEhemochromatosis phenotype $(53,54)$. In $\mathrm{Hfe}^{-/-}$mice, heterozygous loss of Tmprss 6 reduced systemic iron overload, and homozygous loss caused systemic iron deficiency and elevated hepatic hepcidin expression (53). In patients with homozygous $\mathrm{C} 282 \mathrm{Y}$ mutation in the HFE gene, A736V MT2 polymorphism was negatively associated with the penetrance and clinical expression of $\mathrm{HH}$ (54).

Studies on the regulation of MT2 expression in response to iron levels in the body are just emerging, and some results are contradictory. In rats, acute iron deficiency increased the level of MT2 protein but exhibited no effect on its message expression (26). Increased MT2 is expected to suppress hepcidin expression by cleaving plasma membrane HJV in hepatocytes (Figure 1B). Other groups report that the transcription of the MT2-encoding gene TMPRSS 6 can be upregulated either by BMP6 through the BMPsignaling pathway (55) or by hypoxia through both HIF-1 $\alpha$ and HIF- $2 \alpha(56,57)$. Additionally, a recent study showed that hepatocyte growth factor activator inhibitor type 2 (HAI-2) can form a complex with MT2 to inhibit the enzymatic activity of MT2, which indirectly influences the expression of hepatic hepcidin (58). Despite these important observations, the precise mechanism for the regulation of MT2 expression by iron remains to be elucidated.

\section{Hepcidin and the anemia of chronic disease}

The anemia of chronic disease (ACD) is usually associated with disorders leading to chronic immune activation. These disorders include but are not limited to chronic kidney disease, chronic infection, diabetes mellitus, severe trauma, rheumatoid arthritis, Crohn's disease, and cancer $(59,60)$. Patients with ACD have low plasma iron and Tf saturation, despite normal or elevated body iron stores (61). The mechanism underlying this disrupted-iron balance involves hepcidin. Both acute and chronic inflammatory stimuli induce hepcidin expression. IL- 6 or LPS induced hepcidin expression in human hepatocytes $(62,63)$. In mouse hepatocytes, hepcidin expression was induced by IL-6, IL-1 $\alpha$, and IL-1 $\beta$ (64). In vivo studies highlight the role for IL- 6 in promoting inflammation-driven hepcidin expression. The induction of hepcidin and subsequent hypoferremia were observed in wild-type mice that were treated with turpentine as an inflammation model, but not in IL-6-knockout mice under the same treatment (62), implying that the upregulation of hepcidin during inflammation is mediated through IL-6. In a study to measure the response of hepcidin to IL-6 in humans, volunteers were infused with recombinant IL-6. IL-6 stimulated urinary hepcidin excretion and induced hypoferremia, demonstrating a similar response to that in mice (62). The signal for hepatic hepcidin induction by inflammatory stimuli relies on the stimulation of the JAK2/STAT3 pathway (65-67). In response to an inflammatory stimulus, elevated IL-6 binds to its cellular receptor, which activates JAK2 to phosphorylate STAT3. Activated STAT3 translocates into the nucleus and induces hepcidin expression through binding to the STAT3 response element in the hepcidin promoter (Figure 1C). The anemia results from the downregulation of FPN1, which reduces iron efflux from both enterocytes and macrophages into the circulation and thus decreases the available iron for erythropoiesis (5).

Liver-specific knockout of Smad4 results in blunted hepcidin response after IL- 6 administration, implying that an intact BMP/ SMAD signaling pathway is necessary for the upregulation of hepcidin by the inflammatory pathway (19). Blocking BMP signaling inhibits IL-6-induced hepcidin expression in HepG2 cells (27). Consistently, a recent study indicates that inflammation also induces hepatic expression of activin B, a cytokine of the TGF- $\beta$ superfamily, which increases hepcidin expression by activating the BMP-signaling pathway, likely via a type I BMP receptor (68).

\section{Hepcidin and iron regulation in $\beta$-thalassemia}

The regulation of iron by hepcidin is of particular clinical importance in anemia with iron loading, which occurs in $\beta$-thalassemia, a disorder caused by aberrations in the expression of hemoglobin $\beta$ chains. When anemia occurs with iron loading, two opposite hepcidin-regulatory signals coexist: anemia associated with ineffective erythropoiesis being inhibitory and iron loading being stimulatory.

$\beta$-Thalassemia represents one of the most common inherited forms of chronic anemia. The most important clinical manifestation of $\beta$-thalassemia is microcytic, suggesting a dominant negative effect of an erythroid regulator (69). The anemia in $\beta$-thalassemia is attributed to intramedullary hemolysis, increased destruction of existing rbcs, and shortened rbc survival. However, the major cause of morbidity and mortality in $\beta$-thalassemias is iron overload, with iron-induced cardiomyopathy being the leading cause of death in transfusion-dependent thalassemia (70).

Individuals with $\beta$-thalassemia major need blood transfusions every two to five weeks to sustain life. The amount of iron loading in these patients mainly depends on the volume of blood transfused in addition to ineffective erythropoiesis. During transfusion intervals, hemoglobin levels gradually decrease and ineffective erythropoiesis increases. Increased erythropoietic activity reduces hepcidin and increases iron absorption, exacerbating the iron overload (71).

In contrast, people with $\beta$-thalassemia intermedia are not dependent on transfusion therapy. Their iron overload is a result of increased iron absorption from the small intestine due to ineffective erythropoiesis. They absorb three to four times more iron than unaffected individuals and have high plasma iron and low hepcidin levels $(72,73)$. A mouse model of $\beta$-thalassemia intermedia $(t h 3 /+)$ has a similar phenotype $(74,75)$. These mice are heterozygous for mutations in both the $\beta^{\text {minor }}$ and $\beta^{\text {major }}$ genes. The finding that ineffective erythropoiesis can override iron signals suggests the existence of an erythropoietic signal that inhibits hepcidin expression.

\section{Erythropoietic activity suppresses hepcidin expression}

Iron metabolism and erythropoiesis are inextricably interconnected. Erythrocytes require iron incorporation into the heme group to carry oxygen. Without adequate iron, the maturation 


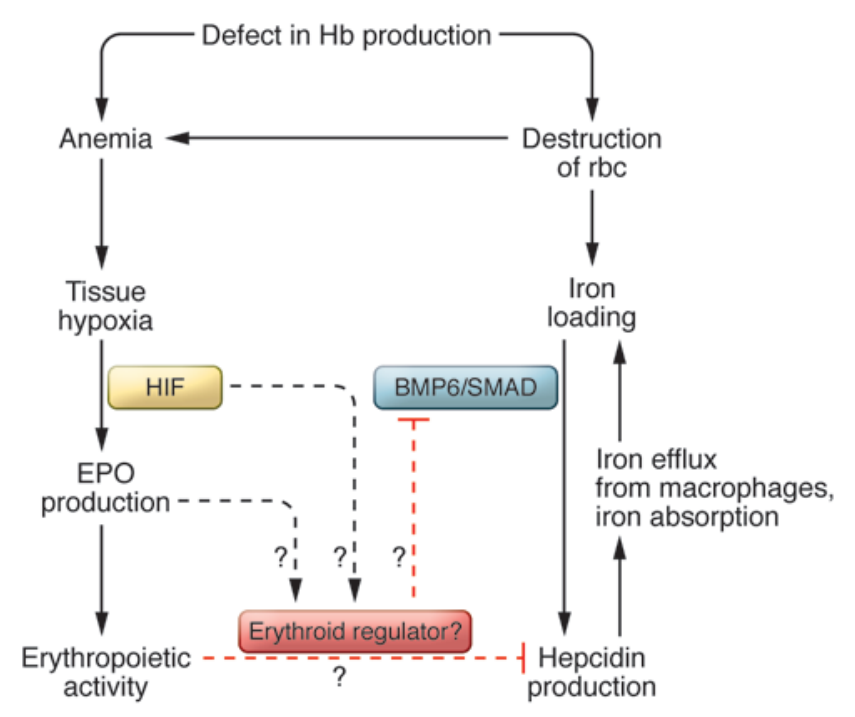

Figure 2

Dysregulation of iron homeostasis in $\beta$-thalassemia. Defective hemoglobin $(\mathrm{Hb})$ synthesis results in increased rbc destruction and anemia. Anemia induces tissue hypoxia, which, in turn, stimulates EPO production. In $\beta$-thalassemia, however, iron overload fails to induce hepcidin expression, suggesting a dominant effect of an erythroid regulator.

of erythrocytes is impaired, resulting in microcytic hypochromic anemia. Most of the iron for erythropoiesis comes from catabolism of senescent rbcs by macrophages in the reticuloendothelial system, with effective erythropoiesis counterbalancing the loss of aged blood cells. Hepcidin expression is downregulated by erythropoietic stimuli such as anemia, hypoxia, and synthetic erythropoietin (EPO) administration $(76,77)$. Physiologically, increased systemic erythropoiesis is a major adaptation to hypoxia. The reduced tissue oxygen level is sensed mainly by the kidney, resulting in increased production of EPO, a key regulator of erythropoiesis (78). EPO binds to EPO receptors on the surface of erythroid progenitors (79), where it prevents their apoptosis and induces the proliferation and differentiation into rbcs $(80,81)$. In mice, stimulation of erythropoiesis by EPO, phlebotomy, or phenylhydrazine suppresses hepcidin expression, indicating that the downregulation of hepcidin involves increased erythropoietic activity and possibly requires the secretion of a putative erythroid regulator (82). The nature of the regulator and whether it is controlled by EPO or erythropoiesis remains to be determined (Figure 2 ).

Though clearly intertwined, the mechanism by which erythropoiesis regulates hepcidin expression is not clear, and the erythroid regulator has yet to be identified. The BMP antagonist growth differentiation factor (GDF15) was upregulated in $\beta$-thalassemia patients and could override the potential effect of iron overload on hepcidin expression (83). GDF15 concentrations in the blood from thalassemia patients were also increased compared with those of healthy individuals (83). However, in healthy humans, iron deficiency or reduced hepcidin expression caused by blood loss was not associated with elevated serum GDF15 $(84,85)$. Thus, GDF15 is unlikely to be involved in the physiological suppression of hepcidin expression under conditions of normal erythropoiesis $(84,85)$.

\section{Hypoxia suppresses hepcidin expression}

Tissue hypoxia directly inhibits hepcidin expression in hepatocytes independently of iron stores in the body (77). Thus, hypoxia may play a role in iron regulation in patients with anemia accompanied by ineffective erythropoiesis. The central mediators of hypoxiainduced erythropoiesis are HIF proteins, of which HIF- $1 \alpha$ and HIF$2 \alpha$ are best characterized. HIF proteins are heterodimers of one $\alpha$ and one $\beta$ subunit. Oxygen, iron, and ascorbate-dependent prolylhydroxylase domain-containing proteins (PHDs) all regulate the stability of the $\alpha$ subunit. Under normoxic conditions, PHDs use 2-oxoglutarate as a cofactor for hydroxylation of HIF $\alpha$-subunits. Hydroxylated HIF $\alpha$-subunits are recognized by the von HippelLindau tumor suppressor (pVHL), which acts as a component of an E3 ubiquitin ligase complex $(86,87)$. The subsequent ubiquitylation targets HIF $\alpha$ subunits for proteasomal degradation. During hypoxic conditions, the hydroxylation is inhibited, thus increasing the stability of the HIF $\alpha$ subunits, and high HIF levels activate a broad range of genes required for hypoxia adaptation.

HIF- $1 \alpha$ was discovered when the mechanism by which hypoxia induces the production of EPO was examined (88, 89). HIF-1 $\alpha$ binds to the enhancer element of the EPO gene and activates its transcription in response to hypoxia. Further, HIF-1 $\alpha$ negatively regulates hepcidin expression by binding to the hepcidin promoter in vivo and reduces hepcidin expression in the mouse liver (90). The dietary iron deficiency-induced hepcidin downregulation is partially blunted in hepatocyte-specific Hif-1 $\alpha$-knockout mice. However, two independent groups reported that hepcidin suppression is not directly regulated by either HIF- $1 \alpha$ or HIF- $2 \alpha$, but depends on increased erythropoietic activity $(91,92)$. Thus, the precise mechanism by which hypoxia suppresses hepcidin expression remains to be determined.

\section{Development of assays to quantify hepcidin}

Several groups have established assays to measure hepcidin levels in plasma because of its importance in iron homeostasis and iron distribution in the body. Abnormally low hepcidin levels contribute to the pathological accumulation of iron in $\mathrm{HH}$ as well as in ineffective erythropoiesis, exemplified by $\beta$-thalassemia. High hepcidin levels are indicative of the ACD and of IRIDA. Mass spectrometry assays are based on the identification of the 25-amino acid form of hepcidin in plasma (93-97). This form of hepcidin binds to FPN1 and targets FPN1 for degradation in the lysosome (5). Comparisons between hepcidin mRNA levels and the levels of the 25-amino acid processed form of hep-

\section{Table 1}

Genetic diseases involving abnormal hepcidin levels

$\begin{array}{llc}\begin{array}{l}\text { Disease } \\ \text { HH }\end{array} & \text { Hepcidin levels/phenotype } & \text { Gene mutated } \\ \text { Type 1 } & \text { Low/iron overload } & \text { HFE } \\ \text { Type 2a } & \text { Low/iron overload } & \text { HJV } \\ \text { Type 2b } & \text { Low/iron overload } & \text { HAMP } \\ \text { Type 3 } & \text { Low/iron overload } & \text { TFR2 } \\ \text { IRIDA } & \text { High/anemia } & \text { TMPRSS6 } \\ \alpha \text { - and } \beta \text {-thalassemia } & \text { Low/iron overload, anemia } & H B A, H B B \\ \text { DMT1 iron overload } & \text { Low/iron overload, anemia } & S L C 11 A 2 \\ \text { Aceruloplasminemia } & \text { Low/iron overload, anemia } & C P \\ \text { Atransferrinemia } & \text { Low/iron overload, anemia } & \text { TF }\end{array}$


Table 2

Molecular targets used to regulate hepcidin expression

\begin{tabular}{llc}
\hline & & \\
Target & Reagent & Reference \\
TMPRSS6 & siRNA & 110 \\
& ASOs & 111 \\
BMPR & BMP6 & 55 \\
& dorsomorphin & 120 \\
FPN1 & LDN193189 & 112,114 \\
BMP6 & minihepcidin & 104,105 \\
& S-HJV.fC & 27,112 \\
BMP6? & anti-BMP6 & 11 \\
STAT3 & Heparin & 115 \\
IL-6R & AG490 & 116,117 \\
hepcidin & anti-IL-6R (tocilizumab) & 118,119 \\
& Spiegelmer N0X-H94 & 108 \\
& Anti-hepcidin & 107 \\
\hline
\end{tabular}

cidin should be able to resolve whether hepcidin processing is controlled. In addition, ELISAs using either double or single antibodies specific for hepcidin have been developed (93, 95, 98-100). In a critical study comparing hepcidin levels by mass spectrometry with those measured by an ELISA assay, Kroot et al. found a close correlation between hepcidin levels measured by both techniques. The ELISA most accurately measured low levels of hepcidin, and mass spectrometry most accurately measured the active form of hepcidin (93).

Hepcidin assays are promising approaches in diagnosing different forms of anemia, such as IDA and ACD (101). Discrimination among IDA, ACD, and ACD/IDA is difficult using the present techniques (102). The distinction between ACD and ACD/IDA is important because IDA can be treated with dietary iron supplementation. Preliminary studies by two groups indicate hepcidin and cellular hemoglobin in reticulocytes can be used to distinguish among IDA, ACD, and ACD/IDA $(101,103)$. Further studies and clinically approved hepcidin assays with higher sensitivity and accuracy are needed to determine whether this approach will be more useful in distinguishing between ACD and ACD/IDA.

\section{Potential therapeutic targets for hepcidin regulation}

Hepcidin is a prime target for the regulation of iron homeostasis in the body because of its specificity in binding FPN1 and the lack of other biological functions aside from its weak defensinlike activity. The iron overload seen in $\mathrm{HH}$ is due to inappropriately low levels of hepcidin (Table 1). A short lipophilic peptide, termed minihepcidin (PR65), was designed to mimic hepcidin and, unlike hepcidin, it can be administered orally. This compound was tested in mouse models of iron overload, and it decreased iron retention and lowered liver and heart iron levels (refs. 104, 105, and Table 2). Minihepcidins have the possibility of ameliorating the $\mathrm{HH}$, which is characterized by low hepcidin levels. Conversely, hepcidin antagonists could be useful for treating leukemias that result from high hepcidin levels (106). A hepcidin antibody developed to block hepcidin binding to FPN1 increased hepcidin clearance in monkeys and lowered hepcidin levels (107). Spiegelmers (mirror image aptamers) directed to hepcidin decreased hepcidin-mediated downregulation of Fpn 1 in a mouse macrophage cell line (108).
The regulation of hepcidin levels to control iron overload have mainly focused on ameliorating iron overload in $\beta$-thalassemia. Overexpression of hepcidin in a mouse model of $\beta$-thalassemia intermedia not only prevented iron overload but also improved anemia (74). Modulation of hepcidin pathways in $\beta$-thalassemic mice through Tf injection increased hepcidin expression, reduced serum EPO levels, and improved anemia (109). Downregulation of TMPRSS6 using an RNAi strategy or the second generation antisense oligonucleotides (ASOs) in murine models of $\mathrm{Hfe} \mathrm{HH}$ and $\beta$-thalassemia intermedia induced hepcidin expression and lessened iron loading of tissues in both models. Moreover the anemia in the $\mathrm{Hbb}(\mathrm{th} 3 /+)$ mice was improved with increased erythropoiesis and rbc survival $(110,111)$.

Modulation of the BMP signaling pathway has been utilized to regulate hepcidin expression. A soluble form of HJV (HJV.Fc) has been used to compete with the endogenous cell-associated form of HJV to inhibit hepcidin expression in mice (27) or in rats (112). Injection of BMP6 increased BMP signaling and hepcidin expression in mice. Unfortunately, the BMP6 injections resulted in peritoneal calcifications (113). Additionally, a recent study indicated that the BMP signaling pathway could be a promising target for the treatment of ACD. Administration of LDN-193189 (a BMP type I receptor inhibitor) or ALK3-Fc (a soluble form of ALK3) prevented the increase in hepcidin expression, the reduction of serum iron, and the development of microcytic anemia in mice caused by induction of inflammation using IL-6 or turpentine (114). Heparin was used to decrease hepcidin levels through the BMP signaling pathway. A combination of in vitro results, in vivo murine studies, and a limited study in humans indicated that heparin reduces hepcidin expression presumably by binding to BMP6 to reduce BMPmediated signaling (115). Alteration of BMP signaling may not be an ideal way to alter hepcidin signaling chronically because BMP signaling alters many other metabolic pathways in the body.

The STAT3 pathway is another target for modulating hepcidin expression. An inhibitor of STAT3 phosphorylation was able to inhibit hepcidin expression in mice and could be a potential candidate for the treatment of anemia associated with high hepcidin levels $(116,117)$. Similarly, an anti-IL-6 receptor antibody has been used to reduce hepcidin levels in patients with Castleman's disease, characterized by high IL-6 levels $(118,119)$. Lowering inflammation and hepcidin levels during active infections has the potential to increase the proliferation of the pathogenic organism by supplying it with more iron.

In summary, the rapid progress in the understanding of how hepcidin controls iron homeostasis and the intense research as to how hepcidin levels can be altered promise new therapies in the future for diseases exacerbated by iron overload or iron depletion.

\section{Acknowledgments}

This work was supported by NIH grants DK054488 (to C.A. Enns), DK072166 (to C.A. Enns), and DK080765 (to A.S. Zhang) and by the Collins Medical Trust (to N.N. Zhao). We wish to thank the reviewers for the careful reading of the manuscript.

Address correspondence to: Caroline A. Enns or An-Sheng Zhang, Department of Cell and Developmental Biology, L215, Oregon Health and Science University, 3181 SW Sam Jackson Park Road, Portland, Oregon 97239, USA. Phone: 503.494.5845; Fax: 503.494.4253; E-mail: ennsca@ohsu.edu (C.A. Enns). Phone: 503.494.5846; Fax: 503.494.4253; E-mail: zhanga@ohsu.edu (A.-S. Zhang). 
1. Krause A, et al. LEAP-1, a novel highly disulfidebonded human peptide, exhibits antimicrobial activity. FEBS Lett. 2000;480(2-3):147-150.

2. Park CH, Valore EV, Waring AJ, Ganz T. Hepcidin, a urinary antimicrobial peptide synthesized in the liver. J Biol Chem. 2001;276(11):7806-7810.

3. Pigeon $\mathrm{C}$, et al. A new mouse liver-specific gene, encoding a protein homologous to human antimicrobial peptide hepcidin, is overexpressed during iron overload. J Biol Chem. 2001;276(11):7811-7819.

4. Nicolas G, et al. Lack of hepcidin gene expression and severe tissue iron overload in upstream stimulatory factor 2 (USF2) knockout mice. Proc Natl Acad Sci U S A. 2001;98(15):8780-8785.

5. Nemeth E, et al. Hepcidin regulates cellular iron efflux by binding to ferroportin and inducing its internalization. Science. 2004;306(5704):2090-2093.

6. Ganz T. Hepcidin and iron regulation, 10 years later. Blood. 2011;117(17):4425-4433.

7. De Domenico I, McVey Ward D, Kaplan J. Regulation of iron acquisition and storage: consequences for iron-linked disorders. Nat Rev Mol Cell Biol. 2008;9(1):72-81.

8. Huang FW, Pinkus JL, Pinkus GS, Fleming MD, Andrews NC. A mouse model of juvenile hemochromatosis. J Clin Invest. 2005;115(8):2187-2191.

9. Niederkofler V, Salie R, Arber S. Hemojuvelin is essential for dietary iron sensing, and its mutation leads to severe iron overload. J Clin Invest. 2005;115(8):2180-2186.

10. Meynard D, Kautz L, Darnaud V, Canonne-Hergaux F, Coppin H, Roth MP. Lack of the bone morphogenetic protein BMP6 induces massive iron overload. Nat Genet. 2009;41(4):478-481.

11. Andriopoulos B Jr, et al. BMP6 is a key endogenous regulator of hepcidin expression and iron metabolism. Nat Genet. 2009;41(4):482-487.

12. Du X, et al. The serine protease TMPRSS6 is required to sense iron deficiency. Science. 2008;320(5879):1088-1092.

13. Folgueras AR, et al. Membrane-bound serine protease matriptase-2 (Tmprss6) is an essential regulator of iron homeostasis. Blood. 2008;112(6):2539-2545.

14. Finberg KE, et al. Mutations in TMPRSS6 cause iron-refractory iron deficiency anemia (IRIDA). Nat Genet. 2008;40(5):569-571.

15. Steinbicker AU, et al. Perturbation of hepcidin expression by BMP type I receptor deletion induces iron overload in mice. Blood. 2011;118(15):4224-4230.

16. Lee DH, et al. Neogenin inhibits HJV secretion and regulates BMP-induced hepcidin expression and iron homeostasis. Blood. 2010;115(15):3136-3145.

17. Babitt JL, Lin HY. The molecular pathogenesis of hereditary hemochromatosis. Semin Liver Dis. 2011;31(3):280-292.

18. Feng XH, Derynck R. Specificity and versatility in tgf-beta signaling through Smads. Annu Rev Cell Dev Biol. 2005;21:659-693.

19. Wang RH, et al. A role of SMAD4 in iron metabolism through the positive regulation of hepcidin expression. Cell Metab. 2005;2(6):399-409.

20. Babitt JL, et al. Bone morphogenetic protein signaling by hemojuvelin regulates hepcidin expression. Nat Genet. 2006;38(5):531-539.

21. Truksa J, Peng H, Lee P, Beutler E. Bone morphogenetic proteins 2,4 , and 9 stimulate murine hepcidin 1 expression independently of Hfe, transferrin receptor 2 (Tfr2), and IL-6. Proc Natl Acad Sci U S A. 2006;103(27):10289-10293.

22. Kautz L, et al. Iron regulates phosphorylation of Smad1/5/8 and gene expression of Bmp6, Smad7, Id1, and Atoh8 in the mouse liver. Blood. 2008;112(4):1503-1509.

23. Corradini E, et al. Serum and liver iron differently regulate the bone morphogenetic protein 6 (BMP6)-SMAD signaling pathway in mice. Hepatology. 2011;54(1):273-284.
24. Ramos E, et al. Evidence for distinct pathways of hepcidin regulation by acute and chronic iron loading in mice. Hepatology. 2011;53(4):1333-1341.

25. Zhang AS, Gao J, Koeberl DD, Enns CA. The role of hepatocyte hemojuvelin in the regulation of bone morphogenic protein- 6 and hepcidin expression in vivo. J Biol Chem. 2010;285(22):16416-16423.

26. Zhang AS, et al. Suppression of hepatic hepcidin expression in response to acute iron deprivation is associated with an increase of matriptase- 2 protein. Blood. 2011;117(5):1687-1699.

27. Babitt JL, Huang FW, Xia Y, Sidis Y, Andrews NC, Lin HY. Modulation of bone morphogenetic protein signaling in vivo regulates systemic iron balance. J Clin Invest. 2007;117(7):1933-1939.

28. Xia Y, Babitt JL, Sidis Y, Chung RT, Lin HY. Hemojuvelin regulates hepcidin expression via a selective subset of BMP ligands and receptors independently of neogenin. Blood. 2008;111(10):5195-5204.

29. Lanzara C, et al. Spectrum of hemojuvelin gene mutations in 1q-linked juvenile hemochromatosis. Blood. 2004;103(11):4317-4321.

30. Papanikolaou G, et al. Mutations in HFE2 cause iron overload in chromosome 1q-linked juvenile hemochromatosis. Nat Genet. 2004;36(1):77-82.

31. Zhang AS, West AP Jr, Wyman AE, Bjorkman PJ, Enns CA. Interaction of hemojuvelin with neogenin results in iron accumulation in human embryonic kidney 293 cells. J Biol Chem. 2005;280(40):33885-33894.

32. Meyerhardt JA, Look AT, Bigner SH, Fearon ER. Identification and characterization of neogenin, a DCC-related gene. Oncogene. 1997;14(10):1129-1136.

33. Kuninger D, Kuns-Hashimoto R, Nili M, Rotwein P. Pro-protein convertases control the maturation and processing of the iron-regulatory protein, RGMc/hemojuvelin. BMC Biochem. 2008;9:9.

34. Silvestri L, Pagani A, Camaschella C. Furin-mediated release of soluble hemojuvelin: a new link between hypoxia and iron homeostasis. Blood. 2008;111(2):924-931.

35. Zhang AS, Anderson SA, Meyers KR, Hernandez C, Eisenstein RS, Enns CA. Evidence that inhibition of hemojuvelin shedding in response to iron is mediated through neogenin. J Biol Chem. 2007;282(17):12547-56

36. Chen W, Sun CC, Chen S, Meynard D, Babitt JL, Lin HY. A novel validated enzyme-linked immunosorbent assay to quantify soluble hemojuvelin in mouse serum. Haematologica. 2013;98(2):296-304.

37. Nili M, Shinde U, Rotwein P. Soluble repulsive guidance molecule $\mathrm{c}$ /hemojuvelin is a broad spectrum bone morphogenetic protein (BMP) antagonist and inhibits both BMP2- and BMP6-mediated signaling and gene expression. J Biol Chem. 2010;285(32):24783-24792

38. Chen W, Huang FW, de Renshaw TB, Andrews NC. Skeletal muscle hemojuvelin is dispensable for systemic iron homeostasis. Blood. 2011; 117(23):6319-6325.

39. Gkouvatsos K, Wagner J, Papanikolaou G, Sebastiani G, Pantopoulos K. Conditional disruption of mouse HFE2 gene: maintenance of systemic iron homeostasis requires hepatic but not skeletal muscle hemojuvelin. Hepatology. 2011;54(5):1800-1807.

40. Gao J, Chen J, Kramer M, Tsukamoto H, Zhang AS, Enns CA. Interaction of the hereditary hemochromatosis protein HFE with transferrin receptor 2 is required for transferrin-induced hepcidin expression. Cell Metab. 2009;9(3):217-227.

41. Goswami T, Andrews NC. Hereditary hemochromatosis protein, HFE, interaction with transferrin receptor 2 suggests a molecular mechanism for mammalian iron sensing. J Biol Chem. 2006;281(39):28494-28498.

42. Zhang AS, Xiong S, Tsukamoto H, Enns CA. Localization of iron metabolism-related mRNAs in rat liver indicate that HFE is expressed predominantly in hepatocytes. Blood. 2004;103(4):1509-1514.

43. Corradini E, et al. Bone morphogenetic protein signaling is impaired in an HFE knockout mouse model of hemochromatosis. Gastroenterology. 2009;137(4):1489-1497.

44. Corradini E, et al. Iron regulation of hepcidin despite attenuated Smad1,5,8 signaling in mice without transferrin receptor 2 or Hfe. Gastroenterology. 2011;141(5):1907-1914.

45. Wallace DF, Summerville L, Crampton EM, Frazer DM, Anderson GJ, Subramaniam VN. Combined deletion of Hfe and transferrin receptor 2 in mice leads to marked dysregulation of hepcidin and iron overload. Hepatology. 2009;50(6):1992-2000.

46. Schmidt PJ, Fleming MD. Transgenic HFEdependent induction of hepcidin in mice does not require transferrin receptor-2. Am J Hematol. 2012;87(6):588-595.

47. D'Alessio F, Hentze MW, Muckenthaler MU. The hemochromatosis proteins HFE, TfR2, and HJV form a membrane-associated protein complex for hepcidin regulation.J Hepatol. 2012;57(5):1052-1060.

48. Johnson MB, Enns CA. Diferric transferrin regulates transferrin receptor 2 protein stability. Blood. 2004;104(13):4287-4293.

49. Velasco G, Cal S, Quesada V, Sanchez LM, LopezOtin C. Matriptase-2, a membrane-bound mosaic serine proteinase predominantly expressed in human liver and showing degrading activity against extracellular matrix proteins. J Biol Chem. 2002;277(40):37637-37646.

50. Silvestri L, Pagani A, Nai A, De Domenico I, Kaplan J, Camaschella C. The serine protease matriptase-2 (TMPRSS6) inhibits hepcidin activation by cleaving membrane hemojuvelin. Cell Metab. 2008;8(6):502-511.

51. Lenoir A, et al. Iron-deficiency anemia from matriptase- 2 inactivation is dependent on the presence of functional Bmp6. Blood. 2011;117(2):647-650.

52. Enns CA, Ahmed R, Zhang AS. Neogenin interacts with matriptase- 2 to facilitate hemojuvelin cleavage. J Biol Chem. 2012;287(42):35104-35117.

53. Finberg KE, Whittlesey RL, Andrews NC. Tmprss6 is a genetic modifier of the Hfe-hemochromatosis phenotype in mice. Blood. 2011;117(17):4590-4599.

54. Valenti L, et al. Effect of the A736V TMPRSS6 polymorphism on the penetrance and clinical expression of hereditary hemochromatosis. J Hepatol. 2012;57(6):1319-1325.

55. Meynard D, et al. Regulation of TMPRSS6 by BMP6 and iron in human cells and mice. Blood. 2011;118(3):747-756.

56. Lakhal S, Schodel J, Townsend AR, Pugh CW, Ratcliffe PJ, Mole DR. Regulation of type II transmembrane serine proteinase TMPRSS 6 by hypoxia-inducible factors: new link between hypoxia signaling and iron homeostasis. J Biol Chem. 2011;286(6):4090-4097.

57. Maurer E, Gutschow M, Stirnberg M. Matriptase-2 (TMPRSS6) is directly up-regulated by hypoxia inducible factor-1: identification of a hypoxiaresponsive element in the TMPRSS6 promoter region. Biol Chem. 2012;393(6):535-540.

58. Maurer E, Gutschow M, Stirnberg M. Hepatocyte growth factor activator inhibitor type 2 (HAI2) modulates hepcidin expression by inhibiting cell surface protease matriptase-2. Biochem J. 2013;450(3):583-593.

59. Rivera S, Liu L, Nemeth E, Gabayan V, Sorensen $\mathrm{OE}, \mathrm{Ganz} T$. Hepcidin excess induces the sequestration of iron and exacerbates tumor-associated anemia. Blood. 2005;105(4):1797-1802

60. Semrin G, et al. Impaired intestinal iron absorption in Crohn's disease correlates with disease activity and markers of inflammation. Inflamm Bowel Dis. 2006;12(12):1101-1106.

61. Ganz T, Nemeth E. Iron imports. IV. Hepcidin and regulation of body iron metabolism. Am J Physiol 
Gastrointest Liver Physiol. 2006;290(2):G199-G203.

62. Nemeth E, et al. IL-6 mediates hypoferremia of inflammation by inducing the synthesis of the iron regulatory hormone hepcidin. J Clin Invest. 2004;113(9):1271-1276.

63. Nemeth E, Valore EV, Territo M, Schiller G, Lichtenstein A, Ganz T. Hepcidin, a putative mediator of anemia of inflammation, is a type II acute-phase protein. Blood. 2003;101(7):2461-2463.

64. Lee P, Peng H, Gelbart T, Wang L, Beutler E. Regulation of hepcidin transcription by interleukin-1 and interleukin-6. Proc Natl Acad Sci U S A. 2005;102(6):1906-1910.

65. Wrighting DM, Andrews NC. Interleukin-6 induces hepcidin expression through STAT3. Blood. 2006;108(9):3204-3209.

66. Verga Falzacappa MV, Vujic Spasic M, Kessler R, Stolte J, Hentze MW, Muckenthaler MU. STAT3 mediates hepatic hepcidin expression and its inflammatory stimulation. Blood. 2007;109(1):353-358.

67. Pietrangelo A, et al. STAT3 is required for IL6-gp130-dependent activation of hepcidin in vivo. Gastroenterology. 2007;132(1):294-300.

68. Besson-Fournier C, et al. Induction of activin B by inflammatory stimuli up-regulates expression of the iron-regulatory peptide hepcidin through Smad1/5/8 signaling. Blood. 2012;120(2):431-9.

69. Peters M, Heijboer H, Smiers F, Giordano PC. Diagnosis and management of thalassaemia. $B M J$ 2012;344:e228.

70. Russo V, et al. Dispersion of repolarization and beta-thalassemia major: the prognostic role of QT and JT dispersion for identifying the highrisk patients for sudden death. Eur J Haematol. 2011;86(4):324-331.

71. Nemeth E. Hepcidin in beta-thalassemia. Ann NY Acad Sci. 2010;1202:31-35.

72. Pippard MJ, Callender ST, Warner GT, Weatherall DJ. Iron absorption and loading in beta-thalassaemia intermedia. Lancet. 1979;2(8147):819-821.

73. Canatan D, Akdeniz SK. Iron and ferritin levels in saliva of patients with thalassemia and iron deficiency anemia. Mediterr J Hematol Infect Dis. 2012;4(1):e2012051.

74. Gardenghi S, et al. Hepcidin as a therapeutic tool to limit iron overload and improve anemia in beta-thalassemic mice. J Clin Invest. 2010;120(12):4466-4477.

75. Gardenghi S, et al. Ineffective erythropoiesis in beta-thalassemia is characterized by increased iron absorption mediated by down-regulation of hepcidin and up-regulation of ferroportin. Blood. 2007;109(11):5027-5035.

76. Vokurka M, Krijt J, Sulc K, Necas E. Hepcidin mRNA levels in mouse liver respond to inhibition of erythropoiesis. Physiol Res. 2006;55(6):667-674.

77. Nicolas $G$, et al. The gene encoding the iron regulatory peptide hepcidin is regulated by anemia, hypoxia, and inflammation. J Clin Invest. 2002;110(7):1037-1044.

78. Wenger RH, Hoogewijs D. Regulated oxygen sensing by protein hydroxylation in renal erythropoietin-producing cells. Amer J Physiol Renal. 2010;298(6):F1287-F1296.

79. Youssoufian H, Longmore G, Neumann D, Yoshimura A, Lodish HF. Structure, function, and activation of the erythropoietin receptor. Blood. 1993;81(9):2223-2236.

80. Koury MJ, Bondurant MC. Erythropoietin retards DNA breakdown and prevents programmed death in erythroid progenitor cells. Science. 1990;248(4953):378-381.

81. Sui X, Krantz SB, Zhao ZJ. Stem cell factor and erythropoietin inhibit apoptosis of human erythroid progenitor cells through different signalling pathways. Br J Haematol. 2000;110(1):63-70.

82. Pak M, Lopez MA, Gabayan V, Ganz T, Rivera S. Suppression of hepcidin during anemia requires erythropoietic activity. Blood. 2006;108(12):3730-3735.

83. Tanno T, et al. High levels of GDF15 in thalassemia suppress expression of the iron regulatory protein hepcidin. Nat Med. 2007;13(9):1096-1101.

84. Tanno T, Rabel A, Lee YT, Yau YY, Leitman SF, Miller JL. Expression of growth differentiation factor 15 is not elevated in individuals with iron deficiency secondary to volunteer blood donation. Transfusion (Paris). 2010;50(7):1532-1535.

85. Ashby DR, et al. Erythropoietin administration in humans causes a marked and prolonged reduction in circulating hepcidin. Haematologica. 2010;95(3):505-508.

86. Maxwell PH, et al. The tumour suppressor protein VHL targets hypoxia-inducible factors for oxygen-dependent proteolysis. Nature. 1999;399(6733):271-275.

87. Kamura T, Sato S, Iwai K, Czyzyk-Krzeska M, Conaway RC, Conaway JW. Activation of HIF1alpha ubiquitination by a reconstituted von HippelLindau (VHL) tumor suppressor complex. Proc Natl Acad Sci U S A. 2000;97(19):10430-10435.

88. Semenza GL, Wang GL. A nuclear factor induced by hypoxia via de novo protein synthesis binds to the human erythropoietin gene enhancer at a site required for transcriptional activation. Mol Cell Biol. 1992;12(12):5447-5454

89. Semenza GL, Nejfelt MK, Chi SM, Antonarakis SE. Hypoxia-inducible nuclear factors bind to an enhancer element located 3 ' to the human erythropoietin gene. Proc Natl Acad Sci U S A. 1991;88(13):5680-5684

90. Peyssonnaux C, et al. Regulation of iron homeostasis by the hypoxia-inducible transcription factors (HIFs). J Clin Invest. 2007;117(7):1926-1932.

91. Liu Q, Davidoff O, Niss K, Haase VH. Hypoxiainducible factor regulates hepcidin via erythropoietin-induced erythropoiesis. J Clin Invest. 2012;122(12):4635-4644.

92. Mastrogiannaki M, et al. Hepatic hypoxia-inducible factor- 2 down-regulates hepcidin expression in mice through an erythropoietin-mediated increase in erythropoiesis. Haematologica. 2012;97(6):827-834.

93. Kroot JJ, et al. Immunochemical and massspectrometry-based serum hepcidin assays for iron metabolism disorders. Clin Chem. 2010;56(10):1570-1579.

94. Houbart V, Cobraiville G, Lecomte F, Debrus B, Hubert P, Fillet M. Development of a nano-liquid chromatography on chip tandem mass spectrometry method for high-sensitivity hepcidin quantitation. J Chromatogr A. 2011;1218(50):9046-9054.

95. Tomosugi $\mathrm{N}$, et al. Detection of serum hepcidin in renal failure and inflammation by using ProteinChip System. Blood. 2006;108(4):1381-1387.

96. Murphy AT, Witcher DR, Luan P, Wroblewski VJ. Quantitation of hepcidin from human and mouse serum using liquid chromatography tandem mass spectrometry. Blood. 2007;110(3):1048-1054.

97. Swinkels DW, et al. Advances in quantitative hepcidin measurements by time-of-flight mass spectrometry. PloS One. 2008;3(7):e2706.

98. Koliaraki V, et al. A novel immunological assay for hepcidin quantification in human serum. PloS One. 2009;4(2):e4581.

99. Ganz T, Olbina G, Girelli D, Nemeth E, Westerman M. Immunoassay for human serum hepcidin. Blood. 2008;112(10):4292-4297.

100.Schwarz P, et al. A novel monoclonal antibody immunoassay for the detection of human serum hepcidin. J Gastroenterol. 2011;46(5):648-656.
101. Thomas C, Kobold U, Balan S, Roeddiger R, Thomas L. Serum hepcidin-25 may replace the ferritin index in the Thomas plot in assessing iron status in anemic patients. Int J Lab Hematol. 2011;33(2):187-193.

102. Cook JD. Diagnosis and management of irondeficiency anaemia. Best Pract Res Clin Haematol. 2005;18(2):319-332.

103.van Santen S, et al. Hepcidin and hemoglobin content parameters in the diagnosis of iron deficiency in rheumatoid arthritis patients with anemia. Arthritis Rheum. 2011;63(12):3672-3680.

104. Ramos E, et al. Minihepcidins prevent iron overload in a hepcidin-deficient mouse model of severe hemochromatosis. Blood. 2012;120(18):3829-3836.

105.Preza GC, et al. Minihepcidins are rationally designed small peptides that mimic hepcidin activity in mice and may be useful for the treatment of iron overload. J Clin Invest. 2011;121(12):4880-4888.

106. Fung E, Sugianto P, Hsu J, Damoiseaux R, Ganz T, Nemeth E. High-throughput screening of small molecules identifies hepcidin antagonists. $\mathrm{Mol}$ Pharmacol. 2013;83(3):681-690.

107.Xiao JJ, et al. Pharmacokinetics of anti-hepcidin monoclonal antibody $\mathrm{Ab} 12 \mathrm{~B} 9 \mathrm{~m}$ and hepcidin in cynomolgus monkeys. Aaps J. 2010;12(4):646-657.

108. Schwoebel F, et al. The effects of the anti-hepcidin Spiegelmer NOX-H94 on inflammationinduced anemia in cynomolgus monkeys. Blood. 2013;121(12):2311-2315.

109. Li H, et al. Transferrin therapy ameliorates disease in beta-thalassemic mice. Nat Med. 2010;16(2):177-182.

110.Schmidt PJ, et al. An RNAi therapeutic targeting Tmprss6 decreases iron overload in $\mathrm{Hfe}^{-/-}$ mice and ameliorates anemia and iron overload in murine beta-thalassemia intermedia. Blood. 2013;121(7):1200-1208.

111. Guo S, et al. Reducing TMPRSS6 ameliorates hemochromatosis and beta-thalassemia in mice. J Clin Invest. 2013;123(4):1531-1541.

112. Theurl I, et al. Pharmacologic inhibition of hepcidin expression reverses anemia of chronic inflammation in rats. Blood. 2011;118(18):4977-4984.

113. Corradini E, et al. BMP6 treatment compensates for the molecular defect and ameliorates hemochromatosis in Hfe knockout mice. Gastroenterology. 2010;139(5):1721-1729.

114. Steinbicker AU, et al. Inhibition of bone morphogenetic protein signaling attenuates anemia associated with inflammation. Blood. 2011;117(18):4915-4923.

115. Poli M, et al. Heparin: a potent inhibitor of hepcidin expression in vitro and in vivo. Blood. 2011;117(3):997-1004.

116.Zhang SP, Wang Z, Wang LX, Liu SJ. AG490: an inhibitor of hepcidin expression in vivo. World $J$ Gastroenterol. 2011;17(45):5032-5034.

117. Fatih N, et al. Natural and synthetic STAT3 inhibitors reduce hepcidin expression in differentiated mouse hepatocytes expressing the active phosphorylated STAT3 form. J Mol Med (Berl). 2010;88(5):477-486.

118. Kawabata H, Tomosugi N, Kanda J, Tanaka Y, Yoshizaki K, Uchiyama T. Anti-interleukin 6 receptor antibody tocilizumab reduces the level of serum hepcidin in patients with multicentric Castleman's disease. Haematologica. 2007;92(6):857-858.

119.Song SN, Tomosugi N, Kawabata H, Ishikawa T, Nishikawa T, Yoshizaki K. Down-regulation of hepcidin resulting from long-term treatment with an anti-IL-6 receptor antibody (tocilizumab) improves anemia of inflammation in multicentric Castleman disease. Blood. 2010;116(18):3627-3634.

120.Yu PB, et al. Dorsomorphin inhibits BMP signals required for embryogenesis and iron metabolism. Nat Chem Biol. 2008;4(1):33-41. 